\title{
Evaluating the Impact of an Intervention to Promote Empathy for Patients with Substance Use Disorder in a Rural Emergency Department
}

\author{
Theresa Poling \\ tapolingfnpbc@gmail.com
}

Follow this and additional works at: https://researchrepository.wvu.edu/etd

Part of the Educational Psychology Commons, Emergency Medicine Commons, and the Substance Abuse and Addiction Commons

\section{Recommended Citation}

Poling, Theresa, "Evaluating the Impact of an Intervention to Promote Empathy for Patients with Substance Use Disorder in a Rural Emergency Department" (2019). Graduate Theses, Dissertations, and Problem Reports. 3883.

https://researchrepository.wvu.edu/etd/3883

This Dissertation is protected by copyright and/or related rights. It has been brought to you by the The Research Repository @ WVU with permission from the rights-holder(s). You are free to use this Dissertation in any way that is permitted by the copyright and related rights legislation that applies to your use. For other uses you must obtain permission from the rights-holder(s) directly, unless additional rights are indicated by a Creative Commons license in the record and/ or on the work itself. This Dissertation has been accepted for inclusion in WVU Graduate Theses, Dissertations, and Problem Reports collection by an authorized administrator of The Research Repository @ WVU.

For more information, please contact researchrepository@mail.wvu.edu. 
Evaluating the Impact of an Intervention to Promote Empathy for Patients with Substance Use Disorder in a Rural Emergency Department

Theresa Poling

Capstone Project Final Paper submitted to the School of Nursing

at West Virginia University

In partial fulfillment of the requirements

for the degree of

Doctor of Nursing Practice in

The School of Nursing

Teresa Ritchie, DNP, Chair

Toni DiChiacchio, DNP

Amy Coffman, DNP

Department of Nursing

Morgantown, West Virginia

2019

Keywords: substance use disorder, empathy, teaching

Copyright 2019 Theresa Poling 


\begin{abstract}
Evaluating the Impact of an Intervention to Promote Empathy for Patients with Substance Use

Disorder in a Rural Emergency Department

Theresa Poling
\end{abstract}

\title{
Background
}

Negative attitudes of health professionals towards patients with SUD are common and contribute to suboptimal health care for this marginalized group of patients (Van-Boekel, Brouwers, Van-Weeghel \& Garretson, 2013).

\section{Objectives}

Promoting empathy in the Emergency Department (ED) has the potential to increase nursing staff's awareness of their attitudes and perceptions toward patients with SUD, thereby decreasing the stigma associated with addiction and improving patient care and patient outcomes. The rationale for implementing this project was to evaluate a tool to promote empathy. This tool was developed by the student researcher based on a literature search and analysis.

\section{Design}

This study used The Drug and Drug Problems Perceptions Questionnaire (DDPPQ) developed in 2003 by Watson, Macleran, Shaw \& Nolan to evaluate the effectiveness of an intervention designed to promote empathy for patients with SUD. The questionnaire was administered to nurses prior to and after the intervention. The intervention, a PowerPoint Presentation, was designed by the DNP student investigator and contained information about the scientific underpinnings of addiction, a state of the union for addiction in Appalachia and storytelling experiences from anonymous patient interviews that occurred during the DNP investigators clinical immersion experiences. The intervention was offered on five different occasions in January and February of 2019. Nonparametric testing was used to evaluate preintervention data with post intervention data. Demographic data was also obtained.

\section{Subjects}

Fifteen participants attended the presentations. Of those 15 , five were not nurses but served other roles in the ED such as technician or registration. Of the 10 participants that were nurses, $80 \%$ returned post-intervention questionnaires $(\mathrm{N}=8)$. 


\section{Results}

Non-parametric, Wilcoxon's Signed Ranks Test was used to evaluate the difference between total pre and total post-test score of the 22 question Drug and Drug Problems and Perceptions Questionnaire (DDPPQ). This finding was statistically significant, $p$ value $=.03$. Statistical significance was noted within two subscales: role adequacy (.05) and self-esteem (.03). A strong correlation was identified between role support and job satisfaction subscales $(r=.86$, $p<.006)$.

\section{Conclusion}

A program to promote empathy in the ED is an effective tool for increasing nursing staff's awareness of their attitudes and perceptions toward patients with SUD. This awareness has the potential to decease the stigma associated with addiction and improve patient care and patient outcomes. Similar programs can be easily incorporated into institutional education curriculum. Larger studies to determine significant relationships between data are recommended. 


\section{Table of Contents}

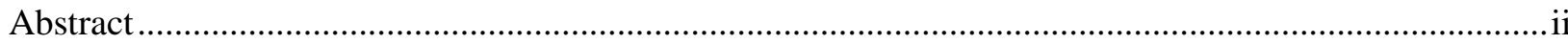

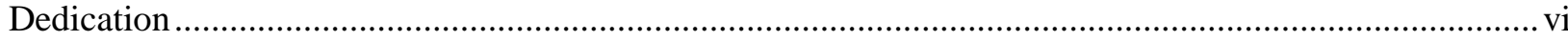

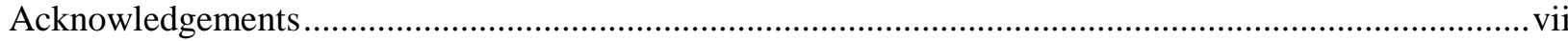

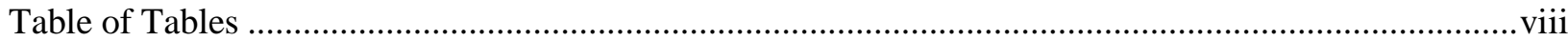

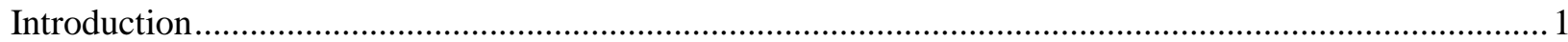

Background and Significance of the project.............................................

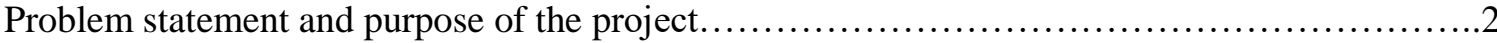

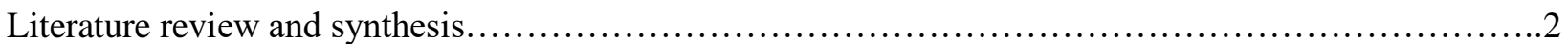

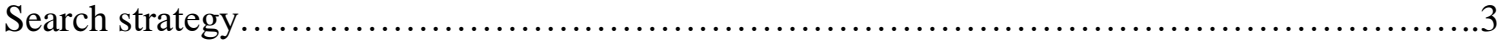

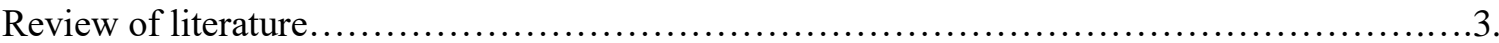

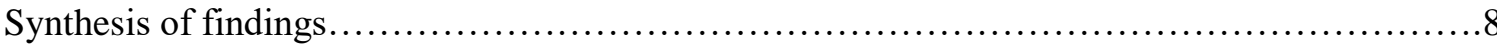

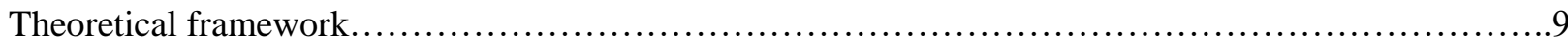

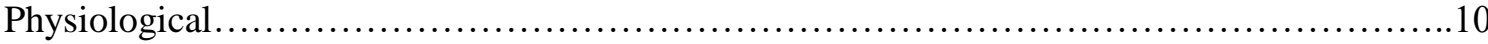

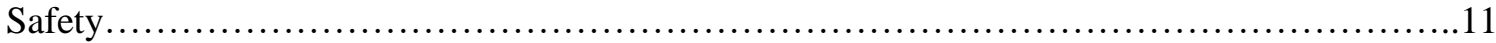

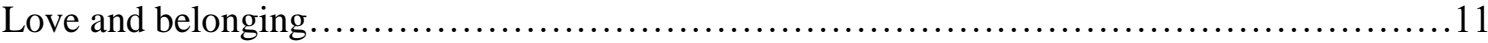

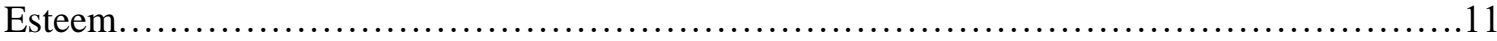

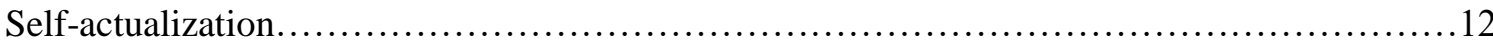

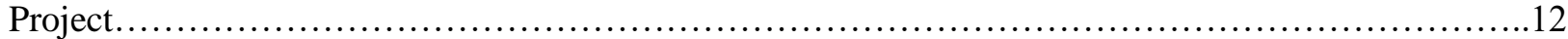

Description of project.............................................................

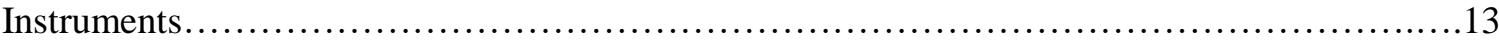

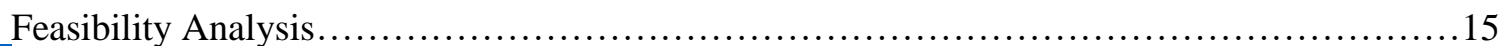

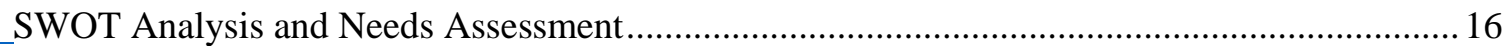

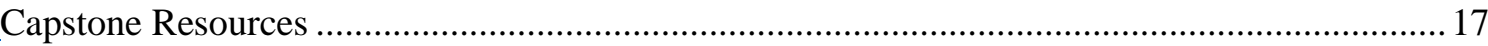

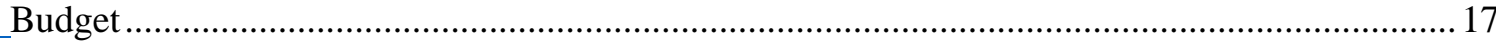

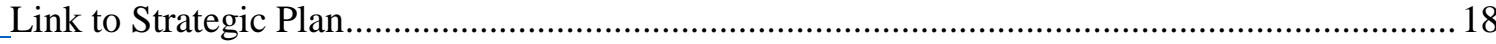

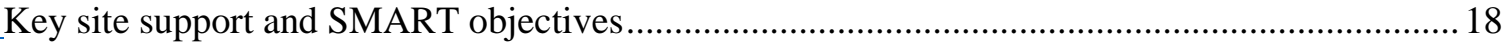

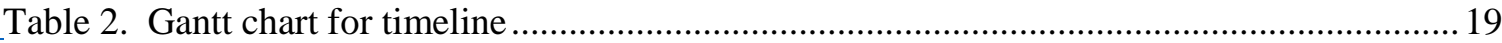

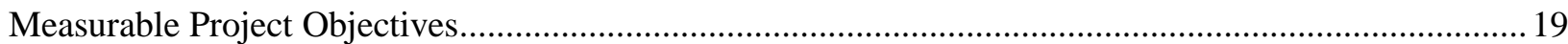

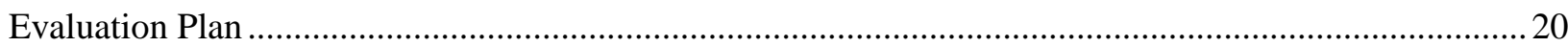

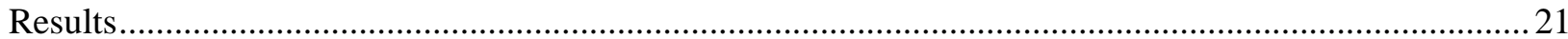




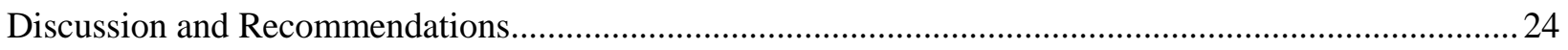

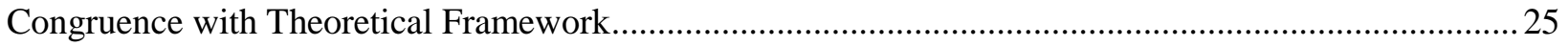

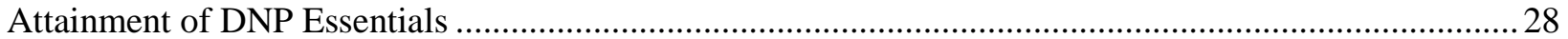

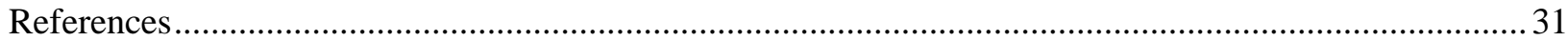

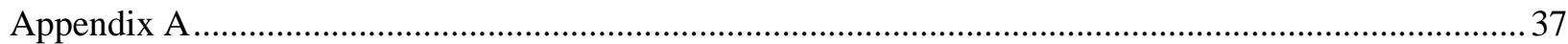

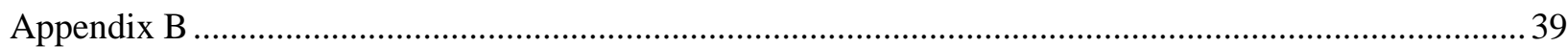

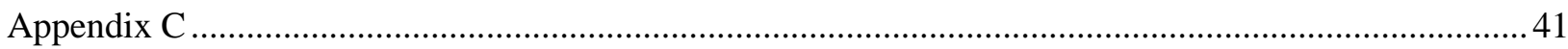

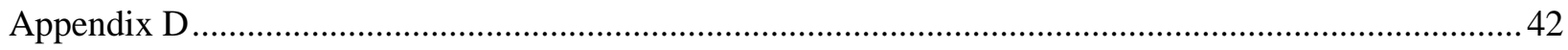


PROMOTING EMPATHY FOR PATIENTS WITH SUBSTANCE ABUSE DISORDER

\section{Dedication}

I am dedicating this project to my tribe. We do the hard things together. We do the good things together. Together, we will never be alone. 


\section{Acknowledgements}

Bountiful tasks are seldom accomplished alone. The pursuit of my doctoral degree was met with encouragement and enthusiasm from my tribe. The subject of substance use disorder is a sensitive one. My tribe has endured great pain in this arena but in the face of it has demonstrated great humanity. Our collective passion is to decrease the stigma of addiction and to promote empathy.

I have also been greatly supported by my committee chair, Dr. Teresa Ritchie who keeps the hours of a vampire, Dr. Toni DiChiacchio who has street cred making her an excellent content expert, Dr. Amy Coffman who helps me through the tough times and Dr. Ubolrat Piamjariyakul who encompasses more statistical knowledge than any human I've ever had the pleasure to work with.

My hope is that one day, substance use disorder will be treated as a chronic disease and not a criminal justice issue. I hope there will be access to treatment for all and disparities will no longer serve as barriers to care. I hope each patient will be met with compassion and support. I hope to save the lives of the victims of this disease and to educate the community on its role in recovery. I hope that opinions founded in fear, bias and prejudice will no longer give rise to the stigma of addiction. 


\section{Table of Tables}

Table 1. Content of the intervention PowerPoint....................................23

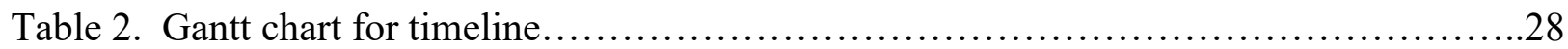

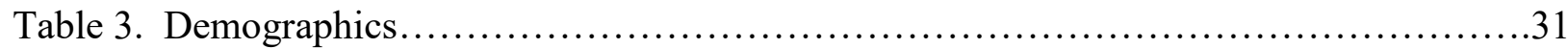

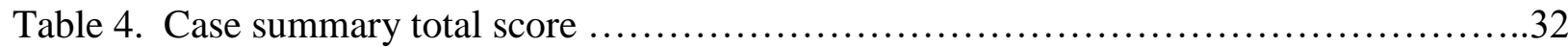

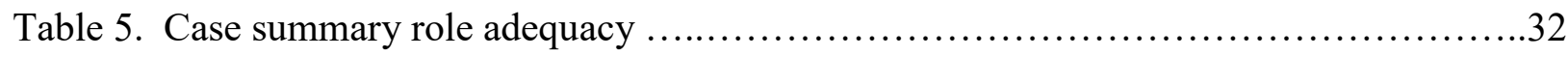

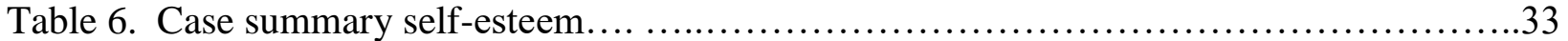




\section{Introduction}

Many factors contribute to the erosion of empathy and compassion in healthcare providers, including fragmentation and discontinuity of care and relationships, increasing operational and administrative requirements, suboptimal staffing and market pressures to increase productivity and efficiency. Compassion fatigue also plays a role in negative attitudes, particularly with patients who have substance use disorder (SUD). A pervasive culture of detached attitudes and behaviors leads to robotic care and reinforces this behavior as a cultural norm. (Lown, 2016).

West Virginia has the highest per capita rate of drug overdose mortality in the United States, with more than 880 deaths in 2016 (DHHR, 2018). Emergency department (ED) nurses are at the forefront of the opioid epidemic and therefore, appear to have the most opportunity for intervention; however, patients with SUD often experience detached care and negative behaviors. Meeting patient's emotional needs is a core aspect of care (Halpern, 2003). A program to promote empathy is one method of improving compassion fatigue.

\section{Background and Significance of the Project}

In 2016, West Virginia had the highest rate of opioid-related overdose deaths in the United States, with 43.4 deaths per 100,000, and the prevalence is increasing in each region of the state (West Virginia Bureau for Behavioral Health and Health Facilities, 2018). In the surveyed years of 2013 to 2014 , about 46,000 individuals aged 12 or older $(2.9 \%$ of all individuals in this age group), were dependent on or abused illicit drugs (Substance Abuse and Mental Health Services Administration $\{$ SAMSA\}, 2018). SUD portends higher morbidity and 
PROMOTING EMPATHY FOR PATIENTS WITH SUBSTANCE ABUSE DISORDER

mortality than any other preventable health condition (National Institute on Drug Abuse \{NIDA\}, 2017). ED nurses are on the forefront of this crisis. Promoting empathy in the ED has the potential to increase nursing staff's awareness of their attitudes and perceptions toward patients with SUD, thereby decreasing the stigma associated with addiction and improving patient care and patient outcomes.

\section{Problem Statement and Purpose of the Project}

Negative attitudes of health professionals towards patients with SUD are common and contribute to suboptimal health care for this marginalized group of patients (Van-Boekel, Brouwers, VanWeeghel \& Garretson, 2013). Patients with SUD can be challenging to care for, leading to compassion fatigue in ED nursing staff. ED nurses would benefit from tools and skills that promote empathy, thereby improving resilience to compassion fatigue. This capstone project sought to cultivate a culture of care with local ED nurses, thereby improving the quality of care for patients with SUD by providing a one hour interactive dialogue on the scientific underpinnings of addiction and tools that promote empathy.

Literature review and synthesis

\section{Search Strategy}

An advanced literature search was conducted in July of 2018 using the following databases: CINAHL with full text, Medline, PsycInfo, Social work Abstracts, Health source: nursing/Academic and PsycArticles. The original search included the key words teaching and empathy and healthcare and was not limited by date. A total of 434 publications ranging from 1977 to 2018 were found. When exact duplicates were removed, the limits of full text, English language, and peer reviewed articles in the last 5 years was added, the search yielded 55 articles. 
The following Inclusion criteria was used: 1) Identification of curriculum or teaching in subject 2) Similar outcomes used to determine effectiveness 3) Summary of findings included 4) Recommendations supported by the reported data. It is important to note that substance abuse was not used as inclusion criteria, as long as empathy was the focus of the teaching, the subject matter did not require exclusion. For example, some of the articles reviewed identified empathy towards patients with disabilities or mental illness. After reviewing 55 articles, 43 publications were excluded based on the following criteria: 1) Lack of identified focus on empathy 2) Lack of identified focus in healthcare 3) Identification of a focus on self-empathy 4) Studies that used patients as intervention group 5) Lack of identified intervention of teaching or promoting empathy. The 12 remaining studies that met inclusion criteria included 5 scholarly articles, one repeated measures design study, one systematic literature reviews, one pilot study, one empirical quantitative study, two descriptive (correlational) research studies and one clinical research study.

\section{Review of Literature}

Miller, S.R. (2014) conducted a repeated measures design study that included 18 narratives from persons with disabilities highlighting authentic representations of their experiences or other information they wanted healthcare professionals to know. Pre- and postassessment measures were evaluated using the Attitude Toward Disabled Persons scale (ATDP), and the Attitudes Toward Patient Advocacy Microsocial scale (AMIA). Evaluation was completed using paired t-test scores. Ninety-five students completed the pre-IRI, pre- and postATDP scale and pre- and post-AMIA. The findings demonstrated significantly increased postmodule scores, validating that a curriculum designed to evoke reflections about attitudes, empathy, and the role of advocacy for healthcare professionals can improve attitudes toward and 
advocacy for persons with disabilities (Miller, 2014). The paired sample t-test use was a strength of this study. The study was limited by its lack of diversity, as most participants were white females without disabilities; therefore, the results may not be generalized to other populations. Furthermore, this study also did not assess the long-term influence of the educational module.

Lown, B. (2016) authored a scholarly article that identified neural networks that generate shared representations of experienced and observed feelings, sensations and actions. When exposed to others experiences, there is an activation of areas in the brain associated with affiliation and reward, demonstrating that empathy can be taught. A strength of this analysis is that it highlights neuronal networks responsible for experiencing compassion and provides a theoretical framework for promoting compassion. Further study is needed to identify if compassion in health care translates into improved patient care experiences, quality of life and clinical outcomes, and health professional job satisfaction, wellness and resilience, are avenues for important future research.

Williams, Brown and McKenna (2013) conducted a quantitative study to aid in the development of a workshop toolkit to promote empathy. The toolkit included a range of empathy-oriented DVD simulations and workshop resources that explored empathic selfreported attitudes. The before and after study design, utilized the Jefferson Scale of Empathy Health Profession - Student version (JSE-HP-S). Two hundred ninety three participants completed the questionnaire with the majority of participants from nursing $(n=59 ; 20.1 \%)$, paramedics $(n=55 ; 18.8 \%)$ and nutrition and dietetics $(n=47 ; 16 \%)$. Paired sample t-test was used to evaluate a statistically significant difference between empathy scores before and at 6 weeks (114.34 versus 120.32; $p<0.0001)$ with a moderate effect size $(d=4.7)$. Qualitative findings, also suggested greater understanding of their personal perceptions of empathy. Further 
research is needed to explore if these results can be replicated to achieve better empathetic behaviors leading to improved therapeutic relationships.

Sng et al. (2014) conducted a descriptive (correlational) research study aimed to determine the local empathy trend, and to identify factors influencing this trend. Eight hundred and eighty-two students completed the JSPE-SV and a self-developed questionnaire. Scores including changes in the three factors comprising the JSPE-SV, were analyzed. Factors one, two and three were perspective taking, compassionate care, and standing in patient's shoes. More time spent with family, and greater amount of community service done, correlated with a higher empathy score. On the other hand, more time spent in individual leisure hours and with significant others correlated with a lower JSPE-SV empathy score. One strength in this study is the value of identifying factors constituting empathy, as very few studies seek this goal. Further studies are needed to replicate the findings.

Fleming, B.D., Thomas, S.E., Shaw, D., Burnham, W.S. \& Charles, L.T. (2015) conducted a pilot study to examine changes in the scores on the Scale of Ethno Cultural Empathy (SEE) for first year nursing $(n=40)$ and dental students $(n=42)$ following an empathy and communication workshop. Participants completed an anonymous online survey that included the SEE, a validated measure of empathy toward people with racial and ethnic backgrounds, different from one's own. This survey was completed at three points throughout the intervention: prior to the intervention (baseline), immediately following the intervention workshop (post-test), and one month following the workshop (follow-up). A strength of this study was the comparison of baseline and post-intervention evaluation for sustainability; the results showed statistically significant increases from baseline to post-intervention on the SEE $(p<.05)$, and these gains were maintained at follow-up. A limitation of this study was the lack of a controlled trial format. 
PROMOTING EMPATHY FOR PATIENTS WITH SUBSTANCE ABUSE DISORDER

Gagan (2017) published a scholarly article that identified a need for personal narrative in empathy education. The use of an anecdote as a tool to teach empathy can be far more engaging and powerful than using sets of complicated data and statistical analysis to inform and educate. The value of this article for this project is in the framework of listening to patient stories, to gain insight into their circumstances. A limitation is that it is not a controlled trial.

Hojat, M., Bianco, J.A., Mann, D., Massello, D., \& Calabrese, L.H. (2015) conducted a descriptive (correlational) research study to examine the magnitude of overlap (shared variance) among three measures that include empathy, teamwork, and an integrative approach to patient care. Three-hundred seventy-three medical students completed the Jefferson Scale of Empathy (JSE), the Jefferson Scale of Attitudes toward Physician-Nurse Collaboration (JSAPNC) and Integrative Patient Care (IPC). Significant overlaps were found among the three measures $(p<0.01)$, ranging from $13 \%(r=0.36)$, between JSAPNC and IPC, to $18 \%(r=0.42)$, between JSE and JSAPNC, and 30\% $(r=0.55)$ between JSE and IPC for the total sample. This is a uniquely beneficial study because no previous studies have been published on the relationships between orientations towards integrative patient care, empathy and teamwork. A limitation is that it was limited to medical students, further studies should be undertaken to determine its transferability to other professional domains.

In 2013, Legere, L., Nemec, P. B., \& Swarbrick, M. provided recommendations in a scholarly article to promote empathy. These researchers identified that careful planning of inperson personal narratives are effective tools for promoting empathy. The personal narrative of lived experiences of recovery can show healthcare providers that recovery is real and possible. Recovery stories can highlight what was helpful and what was a hindrance in the path to recovery. Relationship was a strong method of prompting change. The strength of this article is 
in the framework of promoting empathy by using personal narratives. While it lacks the properties of clinical research, its insight is integral to the foundation of this clinical project.

Post, S. G., Ng, L. E., Fischel, J. E., Bennett, M., Bily, L., Chandran, L., \& ... Roess, M. W. (2014) conducted a quantitative study using the Jefferson Scale of Physician Empathy. The study defined four levels of empathy: routine care, detached empathy, affective empathy and compassionate care. It represented an innovative approach to achieving compassionate care as a deep response to suffering at the affective level and appropriate action to relieve it. Future research is needed to devise strategies on how empathy adversely impacts patients and trainees, as well as methods for applying these levels of empathy.

Plant, Barone, Serwint \& Butani (2015) developed a framework for promoting humanism. These authors recommend reflecting on action after impactful events have occurred. This recommendation could be applied to the ED where impactful events occur commonly and are theorized to play a part in compassion fatigue. The framework includes using factual information and case review, grief responses and other emotions to help cope with grief and to identify lessons learned in the debriefing session. While this is not a randomized control trial, its framework has great application to the ED and will be a valuable form of literature to include in this capstone project.

Wiklund, Gustin, L., \& Wagner, L. (2013) conducted clinical application research that focused on the development of a teaching-learning model enabling participants to understand compassion. During that project four clinical nursing teachers met for a total of 12 hours of experiential and reflective work that aimed at exploring participants' understanding of selfcompassion as a source to compassionate care. Data were interpreted in the light of Watson's Theory of Human Caring and five themes were identified: Being there, with self and others; 
respect for human vulnerability; being nonjudgmental; giving voice to things needed to be said and heard; and being able to accept the gift of compassion from others. A main metaphorical theme, 'the Butterfly effect of Caring', was identified, revealing that the development of a compassionate self and the ability to be sensitive, nonjudgmental and respectful towards oneself contributes to a compassionate approach towards others. Findings demonstrate that compassion is a way of being engaged with another person and where the caregiver compassionately is able to acknowledge both self and other's vulnerability and dignity. The main limitation of the study was the small group size of four clinical nurses who met for 12 hours to complete experiential and reflective work.

Through a systematic literature review, Cohen, L. G., \& Sherif, Y. A. (2014) recognized that the promotion of humanistic values is an essential component of medical education. The authors identified 12 practical tips that are relevant to contemporary practices to be used in promoting and sustaining humanistic values in medical education. The specific recommendations were to strengthen curricula, incorporate empathy, nurture dignity, respect and confidentiality, address humanism across settings, foster role modeling, train students to acquire the habit of humanism, acknowledge and address the hidden curriculum, use multiple assessment tools, sustain a vision that incorporates humanistic values, sustain faculty professional development activities, promote and sustain a robust research agenda, and steep traditions. Findings demonstrate that humanistic values can be taught and that steps can be taken so that medical educators and institutions promote and sustain humanistic values.

\section{Synthesis of Findings}

Evidence from one literature review and one scholarly article demonstrated that humanistic values and empathy can be taught (Cohen \& Sherif, 2014; Lown, 2016). Three 
scholarly articles and one repeated measures design identified the power of utilizing personal patient narrative as a tool for promoting empathy (Gagan, 2017; Legere, Lyn; Nemec, Patricia B.; Swarbrick, Margaret; 2013; Miller, 2014; Plant, Barone, Serwint \& Butani, 2015). One scholarly article discussed the development of a pedagogical model with four levels of growth in empathy: level one, routine care; level two, detached empathy; level three, affective empathy; level four, compassionate care (Post et al., 2014). A pilot study, a quantitative study, and a clinical application of research study identified that workshops to promote empathy were effective (Fleming, Thomas, Shaw, Burnham, \& Charles, 2015; Wiklund, Gustin, L., \& Wagner, L. (2013) Williams, Brown \& McKenna, 2013). Two descriptive (correlational) research studies utilized various forms of the Jefferson Scale of Empathy (Hojat, Bianco, Mann, Massello, \& Calabrese, 2015; Sng et al., 2014) while Miller, 2014, utilized the Attitude Toward Disabled Persons scale (ATDP), and the Attitudes Toward Patient Advocacy Microsocial scale (AMIA). When questionnaires were used, they were reported prior to the intervention, and then repeated immediately post-intervention and at a designated follow-up point.

Empirical evidence demonstrates that empathy in health care practice correlates with improved patient outcomes (Williams, Brown, McKenna, 2013). It has been found that empathy declines during training and practice, and that empathy training needs to be an ongoing part of the education process (Lown, 2016). This literature review validates the need for empathy training, and therefore this supports the conception of teaching empathy. Furthermore, while many frameworks and tools were offered for the teaching curriculum, patient narratives as a tool for promoting empathy was validated.

\section{Theoretical framework: Maslow's Hierarchy of Needs}

Maslow's Hierarchy of Needs is a conceptual theory in psychology that is comprised of a 
five-tier model of human needs. The first four levels physiological, safety, love and belonging, are often referred to as deficiency needs and the top level self-actualization is known as growth or being need (McLeod, 2018). Human beings are motivated by a hierarchy of needs and that motivation is often simultaneously determined by more than one basic need (McLeod, 2018).

The conceptual framework that guided this project was Maslow's hierarchy of needs, due to the parallel between Maslow's goal of self-actualization and the mental health paradigm of reaching one's full potential (Henwood, Derejko, Couture, 2016). While Maslow's hierarchy guides personal growth through achievement of basic deficiency needs towards being needs, it is imperative for health care providers to foster this growth and cultivate a culture of support for those with SUD within the health care system. Maslow later suggested that the pursuit of selfactualization may manifest from frustration over not having one's needs met, rather than from their gratification; that facing adversity and failure can lead to self-actualization (Henwood, Derejko, Couture, 2016). It is also theorized that patients move through the hierarchy levels in a recursive and iterative, rather than linear fashion (Henwood, Derejko, Couture, 2016). Regardless of the trajectory, patients with SUD may require assistance meeting their needs. An understanding of the barriers that patients face may improve empathy on the part of the care giver.

\section{Physiological}

Maslow describes the physiologic needs of food, water, warmth and rest as the foundation of the path to self-actualization. In a recent study, Strike, Wodzinski, Patterson, and Wilkinson demonstrated that $54.5 \%$ of drug users reported that on a daily or weekly basis, they did not have enough to eat because of a lack of money, while $22.1 \%$ reported this type of food insecurity on a monthly basis (2012). Housing insecurity is also a real problem with those with 
substance use disorder. Although obtaining an accurate, recent count is difficult, in January of 2016, Housing and Urban Development (HUD) estimated that around 200,000 homeless persons have a chronic substance use disorder.

\section{Safety}

The relationship between interpersonal violence/trauma and substance use disorders is significant. Substance abuse has been found to co-occur in 40-60\% of intimate partner violence cases (Soper, 2014). Trauma is often experienced or witnessed; it can involve serious injury or a threat to one's self or others, or possible death. Patients are also at risk for health problems such as hepatitis B and C, human immunodeficiency virus (HIV), endocarditis, cellulitis and overdose (NIDA, 2018). The responses to these events include intense fear, helplessness and horror. Parallel harm reduction programs take aim at ensuring public safety during times of addiction (Logan \& Marlatt, 2010).

\section{Love and Belonging}

The psychological need of love and belonging is often compromised in patients with SUD. Lack of social interaction can lead to social anxiety, depression and loneliness. The stigma associated with addiction may play a role in maintaining substance use disorders and increasing the likelihood of relapse (Paquette, Syvertsen, Pollini, 2018). The need for love and belonging are especially strong for children of patients with SUD. These children may cling to parents who are either neglectful or abusive towards them, overriding safety needs which typically comes first (Sullivan, 2010). Healthcare providers may play a negative role in love and belonging through detached care (Lown, 2016). It is important to foster compassionate care with all patients, but particularly patients with SUD.

\section{Esteem}


PROMOTING EMPATHY FOR PATIENTS WITH SUBSTANCE ABUSE DISORDER

Maslow classified esteem needs in two categories, the desire for esteem for one's self and the desire for respect from others (McLeod, 2018). Patients often adopt the stigma assigned to them by others (Van-Boekel, Brouwers, Van-Weeghel \& Garretson, 2013). Healthcare providers are in the unique position to positively affect esteem for the patient with SUD.

\section{Self-actualization}

For the patient with SUD, reaching the level of self-actualization aligns with the reaching of one's full potential (Henwood, Derejko, Couture, 2016). When shared representations evoke empathic concern or compassion for another's painful situation, humans experience altruistic motivation to help others (Lown, 2016). Healthcare providers can assist patients in their path to recovery by meeting their basic needs; this, in kind, helps others achieve altruism.

\section{Project}

\section{Description of the Project}

The purpose of this capstone project was to cultivate a culture of care with local ED nurses, thereby improving the quality of care for patients with SUD. The tool used to achieve this goal was a one hour interactive dialogue designed by the student investigator. Emergency room nurses in a small rural hospital in northern WV were included as participants. All participants received an informative email describing the project one month prior to the intervention. Consent form, demographic sheet, and a pink color coded, pre-intervention questionnaire was completed immediately prior to the intervention. The intervention was offered on five different occasions for off duty nurses in January and February, 2019 in a private board room on the hospital campus. It was designed by the DNP student investigator, and the content included information about the scientific underpinnings of addiction, a state of the union for 
PROMOTING EMPATHY FOR PATIENTS WITH SUBSTANCE ABUSE DISORDER

addiction in Appalachia, and storytelling experiences from anonymous patient interviews that occurred during the DNP investigators clinical immersion experiences. All data received was maintained in a locked office in the nurse manager's office until it was secured by the student investigator and placed under lock in a private office. All information was de-identified.

\section{Instruments}

The pre-intervention questionnaire used in this study was the Drug and Drug Problems Perceptions Questionnaire (DDPPQ), developed in 2003 as 29 questions by Watson, Macleran, Shaw \& Nolan. In 2007, after analysis of the questionnaire's test-retest reliability, Watson, Maclaran \& Kerr confirmed the DDPPQ's construct validity and participants confirmed the content validity of the abbreviated 22 question tool. They determined this questionnaire to be a valid and reliable tool which can be used to measure attitudes of people in relation to working with SUD patients (Appendix A). The scale for the questionnaire ranged from a value of 1 (strongly agree) to 7 (strongly disagree). Thus the score of the response options were reversed so the high score reflected positive attitude. Questions 15-18 were negatively worded and already worded in the right direction, therefore the response options of these questions were not reversed.

Prior to the intervention, demographic data was collected from participants and included age, gender, years in nursing, years in the ED and highest degree obtained. The 22- Drug and Drug Problems Perceptions Questionnaire (DDPPQ) was used to collect data from nurse participants (Watson, Maclaran, Kerr, 2007). The questionnaires include 5 subscales: role adequacy (7 items), role support (3 items), job satisfaction (4 items), self-esteem (5 items) and role legitimacy (3 items). The Cronbach alpha score of DDPPQ was reported as <.70 (Watson, Macleran, Shaw, Nolan, 2003).

\section{Intervention}


The content of the intervention was designed by the student investigator. It was titled 'promoting empathy for patients with substance use disorder' and included objectives, the current state of the union in Appalachia, the scientific underpinnings of addiction, a narrative recount of three patient stories, the theoretical framework of Maslow, the role of the healthcare provider in the patient's outcome, tools for empathizing, and a vision of sustainability of this project. The content of the intervention is included in Table 1.

\section{Table 1. Content of the intervention PowerPoint}

I. Goals of the project
a. To advance a culture of caring in the ED
b. Short term change-change in awareness
c. Intermediate change-change in approach
d. Long term change-improved patient outcomes

II. SUD data, including current state of the union in Appalachia
a. Incidence
b. Prevalence
c. Morbidity
d. Mortality

III. Scientific underpinnings of addiction
a. Neurobiology
b. Social aspects
c. Behavioral aspects
d. Levels of empathy
1. Level one: routine care
2. Level two: detached empathy
3. Level three: affective empathy
4. Level four: compassionate care

IV. SUD patient stories
a. Emma
b. Sam
c. Max

VI. Linked patient needs with Maslow's hierarchy
a. Physiological
b. Safety
c. Love and belonging
d. Esteem 


\section{e. Self-actualization}

VII. Role of the healthcare provider in the patient's outcome
a. Meeting the safety need
b. Meeting the love and belonging need

c. Meeting the esteem need

VIII. Tools for empathizing
a. Eye contact
b. Touch
c. Statements like I'm sorry you are struggling with this
d. Information sharing (debriefing if possible)
e. Provide information for follow-up

IX. Vision of sustainability of project
a. Project evaluation
b. Share evaluation with key stakeholders
c. Pulse check with reminders for staff
d. Annual ED training
e. Obstetrics training

Immediately after the intervention, the post-intervention blue color coded DDPPQ was given to the participants in a self-addressed, stamped envelope with instructions to reflect on the information from the intervention and complete the questionnaire in 1-2 weeks. Participants were instructed to either return the completed questionnaire via mail to the DNP project investigator, or return it in to the ED Director. The rationale for implementing this project was that promoting empathy in the ED had the potential to increase awareness of attitudes and perceptions about those with SUD. Meeting patient's emotional needs is a core aspect of care (Halpern, 2003). Furthermore, this would result in decreasing the stigma associated with addiction and ultimately, improve patient care and patient outcomes.

\section{Feasibility Analysis}

Negative attitudes of health professionals toward patients with SUD are common and contribute to suboptimal health care for this marginalized group of patients (Van-Boekel, Brouwers, Van-Weeghel \& Garretson, 2013). The author of this DNP project identified a need to 
promote empathy among ED nurses based on personal observation, and patient and family feedback. This DNP student investigator practicing as a FNP in a family practice clinic has directly observed fellow healthcare provider's negative attitudes toward patients with SUD. Specific examples of negative attitudes from healthcare providers toward SUD patients includes patient reports of robotic, disengaged and occasionally hostile care. Healthcare providers have repeated negative comments about overdose patients 'getting what they deserve' and the general pervasive culture of the ED supports this mentality. Informal interviews of this DNP student investigator with ED nurses corroborates this finding. Based on evidence of the literature review, there is a strong precedent for the ability to promote empathy through storytelling of patient experiences. It is anticipated that this intervention will encourage healthcare provider empathy toward patients with SUD while in the ED.

Sustainability of empathy is paramount to the success of this project and of real practice change. After statistical analysis of this project, the intervention will be integrated into annual training for all departments at DMC. The DDPPQ will be utilized to evaluate ongoing attitude and perception change.

\section{SWOT Analysis and Needs Assessment}

A Strengths, Weaknesses, Opportunities and Threats (SWOT) Analysis was conducted on the proposed intervention. A SWOT analysis is a comprehensive tool that helps identify barriers and strengths of a planned project (Morrison, 2011). Internal strengths and weaknesses along with external opportunities and threats were identified. Internal strengths include the opportunity to impact quality of care for a marginalized population. Internal weaknesses identified include a potential for a lack of support from key stakeholders due to negative attitudes from ED staff mandated to attend a lecture on empathy. External opportunities include a potential for local marketing to emphasize a culture of caring at a rural ED. External threats are made up of biases 
PROMOTING EMPATHY FOR PATIENTS WITH SUBSTANCE ABUSE DISORDER

and prejudices towards patients with SUD and opposition to parallel harm reduction and current treatment modalities for patients with SUD.

There were no extraordinary privacy, confidentiality, or security issues and no anticipated technical constraints with current staff skills. The proposed change didn't place unacceptable demands on any resources required for the development, testing, functional or clinical environments. There was no change in workflow including the sequence, dependencies, effort, or duration of any tasks currently in practice. There were no technical issues or limitations.

\section{Capstone Resources}

Key stakeholders identified in this practice change include the Chief Operating Officer, the Director and staff of the Emergency Department, the Education Director, the Chaplain and the marketing department at the intervention site. The staff in the intervention was made up of Registered Nurses (RN) and Licensed Practical Nurses (LPN). This project had immense support of all the key stakeholders.

\section{Budget}

Functional requirements included the administration boardroom for the presentation, projector equipment and a laptop. This DNP student was the primary interventionist. The proposed budget to cover implementation and organization costs is included (Appendix B). The cost of a nurse practitioner implementing the project was $\$ 55$ per hour. However, as this project was implemented as a DNP capstone project, it was at no cost to the institution. Questionnaires to be completed by project participants were printed at a cost of $\$ 0.10$ per page for a total of $\$ 10$, other project supplies were estimated at $\$ 50$ and included as part of the student investigator donation. The PowerPoint talk was developed as part of the DNP student investigator's capstone project and was included as donated time. Travel expenses were estimated at $\$ 75.60$ and were included as donated investigator time. The project was incentivized by paying attendees their 
PROMOTING EMPATHY FOR PATIENTS WITH SUBSTANCE ABUSE DISORDER

hourly wage plus benefits for one hour and by giving continuing education units (CEU), this was estimated based on staff RN and LPN salaries at \$911.64 and were covered as an organizational contribution. A certificate for a free beverage from the hospital cafeteria was also given at the end of the intervention as an organizational contribution.

\section{Link to Strategic Plan}

This project aligned with the Davis Medical Center organization vision of 'We Bring Better Health to Life' in that studies show compassionate care improves patient outcomes (DMC, 2016). Patients with SUD are a vulnerable population and deserving of better health in their life. This project also aligned with the organization mission of 'We Care for Life' as empathy is an expression of care (DMC, 2016). Patients with SUD often experience detached care. Promoting empathy emphasizes the importance of the DMC mission. Finally, this project aligned with the organization values of safety, quality, teamwork, trust, respect, courtesy, because all of these values are improved with compassionate care (DMC). As healthcare providers, we must acknowledge that we have a responsibility to all patients regardless of circumstances. While each of the values are important, respect holds particularly true for patients with SUD.

\section{Key site support and SMART objectives}

Key site support was given in the form of a letter from the hospital's Chief Operating Officer (Appendix C). A specific, measurable, achievable, relevant, time-oriented (SMART) Work-plan was outlined with realistic timeframes for project completion (Appendix D) and was used as a road map for the project from inception to completion. SMART goals align organizational strategic initiatives with goals that can be obtained (HealthStream, 2018). A Gantt timeline was developed for strategic project planning (table 2). 


$\begin{array}{clll}\text { Table 2. Gantt chart for timeline } & & \\ 1 & 9 / 1 / 2018 & 12 / 1 / 2018 & \begin{array}{l}\text { Began clinical immersion } 120 \\ \text { hours }\end{array} \\ 2 & 8 / 21 / 2018 & 9 / 25 / 2018 & \text { Submitted DNP paper revisions } \\ 3 & 10 / 01 / 2018 & 10 / 02 / 2018 & \text { Met with WVU committee } \\ 4 & 12 / 15 / 2018 & 12 / 19 / 2018 & \text { IRB submission/approval received } \\ 5 & 12 / 20 / 2018 & 12 / 25 / 2018 & \text { Emailed announcement to ED } \\ 6 & 11 / 1 / 2018 & 1 / 1 / 2019 & \text { Developed intervention } \\ 7 & 1 / 18 / 2019 & 2 / 12 / 2019 & \text { Delivered intervention and pre- } \\ & & & \text { intervention DDPPQ } \\ 8 & 1 / 1 / 2019 & 5 / 1 / 2019 & \text { Continued immersion } 180 \text { Hours } \\ 9 & 2 / 12 / 2019 & 3 / 1 / 2019 & \text { Evaluated data } \\ 10 & 3 / 1 / 2019 & 4 / 1 / 2019 & \text { Completed paper } \\ 11 & 4 / 12 / 2019 & 4 / 12 / 2019 & \text { Oral defense } \\ 12 & 5 / 1 / 2019 & 5 / 15 / 2019 & \text { Graduation } \\ 13 & 5 / 1 / 2019 & 5 / 12 / 2019 & \text { ETD submission } \\ 14 & 7 / 1 / 2019 & 7 / 15 / 2019 & \text { Share data with key } \\ & & & \text { stakeholders } \\ 15 & 7 / 15 / 2019 & 8 / 1 / 2019 & \text { Ongoing sustainability efforts }\end{array}$

\section{Measurable Project Objectives}

The objective of this capstone project was to promote empathy for patients with SUD in the ED. This DNP student investigator hypothesized that a one hour interactive discussion utilizing a PowerPoint presentation that promoted empathy to ED staff would increase awareness of attitudes and perceptions about those with SUD, the stigma associated with addiction will decrease thereby improve patient care and patient outcomes.

- The short term objective was a change in awareness in attitudes and behaviors towards patients with SUD. 
- The intermediate objective was a change in the healthcare providers approach to the patient.

- The long term objective was improved patient outcomes. Success of this project was due in part to organizational and participant buy-in for practice change within the system.

\section{Evaluation Plan}

To evaluate the short term objective of a change in awareness in attitudes and behaviors towards patients with SUD, the DDPPQ was administered 1 to 2 weeks after the intervention. Though not part of this capstone, to evaluate the intermediate objective of a change in the healthcare providers approach to the patient, the DDPPQ will be measured 3 months after the intervention. To evaluate the long term objective of improved patient outcomes, the DDPPQ will be given annually. Data from the DDPPQ was statistically analyzed using version 25, Statistical Package for the Social Science (SPSS). The data analysis will be made available to key stakeholders for ongoing sustainability. As the alternative hypothesis was supported, empathy training will be given to the remaining ED staff, the obstetrics department due to the high rate of neonatal abstinence syndrome (NAS) prevalence and all hospital staff that provide direct patient care. Sustainability will be promoted during ED meetings aimed at evaluating and improving patient experiences. The ED nurse manager is committed to continuing open discussions about care of patients and ongoing fostering of empathy for SUD patients in the ED.

\section{Results from Pre- and Post-Test}

\section{Data Analysis}


Descriptive statistics frequencies, mean, and percent were used to analyze the Demographic Data. For DDPPQ data, the data did not meet the normality of distribution, thus the non-parametric Wilcoxon's was used and reported as $\mathrm{Z}=2.240,(p=.03)$.

\section{Results}

The demographics measured included age, race, gender, years in nursing, years in nursing in the ED, and highest nursing education received. Of the 10 nurses participating in the intervention, $80 \%$ returned the post-intervention questionnaire. More than $66 \%$ of the participants were between the ages of 40-49. One hundred percent of the participants were white. Twenty percent of participants were male. Eighty percent of participants had more than six years in nursing and $60 \%$ had more than six years in the ED. There was a correlation between years of nursing and years in the ED $r=.85, p=.01$. Sixty percent had a bachelor's degree in nursing.

Table 3. Demographics 


\begin{tabular}{|l|l|l|}
\hline Characteristics & Count & $\%$ \\
\hline Age $(\mathrm{n}=10)$ & & \\
$18-29$ & $\mathrm{~N}=1$ & $10 \%$ \\
$30-39$ & $\mathrm{~N}=2$ & $20 \%$ \\
$40-49$ & $\mathrm{~N}=3$ & $30 \%$ \\
$50-59$ & $\mathrm{~N}=3$ & $30 \%$ \\
$>60$ & $\mathrm{~N}=1$ & $10 \%$ \\
\hline Gender $(\mathrm{n}=10)$ & & \\
Female & $\mathrm{N}=8$ & $80 \%$ \\
Male & $\mathrm{N}=2$ & $20 \%$ \\
\hline Race (n=10) & 10 & 100 \\
Caucasian & & \\
\hline Years in nursing & & \\
$1-5$ & $\mathrm{~N}=2$ & $20 \%$ \\
$6-10$ & $\mathrm{~N}=3$ & $30 \%$ \\
$11-15$ & $\mathrm{~N}=1$ & $10 \%$ \\
$16-20$ & $\mathrm{~N}=1$ & $10 \%$ \\
$21-25$ & $\mathrm{~N}=2$ & $20 \%$ \\
$>26$ & $\mathrm{~N}=1$ & $10 \%$ \\
& & \\
\hline Years ED DMC & & \\
$1-5$ & $\mathrm{~N}=4$ & $40 \%$ \\
$6-10$ & $\mathrm{~N}=3$ & $30 \%$ \\
$11-15$ & $\mathrm{~N}=1$ & $10 \%$ \\
$16-20$ & $\mathrm{~N}=1$ & $10 \%$ \\
$21-25$ & $\mathrm{~N}=1$ & $10 \%$ \\
$>26$ & & \\
\hline Highest Degree & & \\
LPN & $\mathrm{N}=0$ & \\
ADN & $\mathrm{N}=4$ & \\
BSN & $\mathrm{N}=6$ & $\mathrm{~N}=0$ \\
MSN & $\mathrm{N}=0$ & \\
DNP & & \\
\hline
\end{tabular}

Ten nurses completed the pre-intervention questionnaire $(n=10)$, eight nurses returned the post-intervention questionnaire ( $\mathrm{n}=8)$. SPSS 25 was used to analyze the data. Non-parametric, Wilcoxon's Signed Ranks Test was used to evaluate the difference between total pre and total 
post-test score of the 22 question Drug and Drug Problems and Perceptions Questionnaire (DDPPQ). This finding was statistically significant, $(\mathrm{Z}=2.24, p=.03)$. Seven out of eight $(87.5 \%)$ of participants reported increased score 2 weeks after the intervention. Pre-test and post-test were conducted on each subscale of DDPPQ. Statistical improvement was noted between pre and post on two subscales: role adequacy (.05) and self-esteem (.03). Z score was calculated by pre score, post score. There was statistical significance on two subscales; role adequacy $(Z=-1.95, p$ $=.05)$ and self-esteem $(Z=-2.20, p=.03)$. A Strong correlation was identified between role support and job satisfaction subscales $(r=.86, p<.006)$. No statistical differences were noted on role support, job satisfaction or role legitimacy.

\section{Table 4. Total score case summaries}

\begin{tabular}{|l|l|ll|}
\hline Participant ID & $\begin{array}{l}\text { Pre-Test Total } \\
\text { Score }\end{array}$ & $\begin{array}{l}\text { Post-Test Total } \\
\text { Score }\end{array}$ \\
\hline 1 & 108 & $116 \quad$ (increase) \\
\hline 3 & 97 & 91 & (decrease) \\
\hline 4 & 103 & $117 \quad$ (increase) \\
\hline 7 & 101 & $114 \quad$ (increase) \\
\hline 8 & 99 & 119 & (increase) \\
\hline 9 & 90 & 107 & (increase) \\
\hline 11 & 103 & $108 \quad$ (increase) \\
\hline 12 & 81 & 120 (increase) \\
\hline
\end{tabular}

Table 5. Case summary role adequacy

\begin{tabular}{|c|c|c|c|}
\hline Participant ID & $\begin{array}{c}\text { Role adequacy } \\
\text { pre scale }\end{array}$ & $\begin{array}{c}\text { Role adequacy } \\
\text { post scale }\end{array}$ & $\begin{array}{c}\text { Role adequacy } \\
\text { difference }\end{array}$ \\
\hline 1 & 39 & 40 & 1.00 \\
\hline
\end{tabular}




\begin{tabular}{|c|c|c|c|}
\hline 3 & 32 & 32 & .00 \\
\hline 4 & 36 & 39 & 3.00 \\
\hline 7 & 27 & 34 & 7.00 \\
\hline 8 & 41 & 48 & 7.00 \\
\hline 9 & 23 & 34 & 11.00 \\
\hline 11 & 37 & 34 & -3.00 \\
\hline 12 & 19 & 48 & 19.00 \\
\hline
\end{tabular}

Table 6. Case summary Self-esteem

\begin{tabular}{|c|c|c|c|}
\hline & $\begin{array}{c}\text { Self-esteem pre } \\
\text { scale }\end{array}$ & $\begin{array}{c}\text { Self-esteem post } \\
\text { scale }\end{array}$ & $\begin{array}{c}\text { Self-esteem } \\
\text { difference }\end{array}$ \\
\hline 1 & 19 & 26 & 7.00 \\
\hline 3 & 18 & 18 & .00 \\
\hline 4 & 18 & 22 & 4.00 \\
\hline 7 & 28 & 30 & 2.00 \\
\hline 8 & 20 & 24 & 4.00 \\
\hline 9 & 18 & 26 & 8.00 \\
\hline 11 & 24 & 32 & 8.00 \\
\hline 12 & 28 & 27 & -1.00 \\
\hline
\end{tabular}

Additional analysis was completed to examine the psychometric properties of the DDPPQ. Cronbach alpha $(\alpha)$ reliability score was conducted on total scale $(a=.55)$ and subscales: role legitimacy $(a=.53)$, role support $(a=.94)$, self-esteem $(a=.52)$, job satisfaction $(\mathrm{a}=-.99)$, role adequacy $(\mathrm{a}=.89)$.

\section{Discussion and Recommendations}

The purpose of this capstone project was to evaluate the impact of an intervention to promote empathy for patients with substance use disorder. The reliability of the DDPPQ as a tool to evaluate empathy was evaluated using Cronbach's Alpha. Due to negative responses on questions 15-18 and small sample size, the overall alpha is .56. The negative wording on the questionnaire was potentially confusing for the participant to answer. The Cronbach alpha of the 
PROMOTING EMPATHY FOR PATIENTS WITH SUBSTANCE ABUSE DISORDER

reverse scores on self-esteem was low Alpha =.52. However, each subset was $>.70$, thus the instrument is still reliable to detect differences in this small sample size.

\section{Congruence with Theoretical Framework}

The findings of this project are congruent with the theoretical framework that guided this project, Maslow's hierarchy of needs. The conceptual framework drew a parallel between Maslow's goal of self-actualization and the mental health paradigm of reaching one's full potential (Henwood, Derejko, Couture, 2016). Maslow describes the physiologic needs of food, water, warmth and rest as the foundation of the path to self-actualization. Data highlighting food and housing insecurities was reviewed as part of the interactive dialogue intervention. Acknowledging the struggle of those with SUD to meet their basic needs emphasizes the need to offer compassionate care to this population.

The relationship between interpersonal violence/trauma and substance use disorders is significant. Having safety needs met is an imperative step in the recovery process. ED nurses are in the unique position of being able to promote safety for this population.

The stigma associated with addiction may play a role in maintaining substance use disorders and increasing the likelihood of relapse (Paquette, Syvertsen, Pollini, 2018). As healthcare providers, tools that promote empathy such as eye contact, touch, and genuine engagement has the ability to decrease the loneliness and hopelessness associated with SUD. Patients often adopt the stigma assigned to them by others (Van-Boekel, Brouwers, Van-Weeghel \& Garretson, 2013). Healthcare providers have the ability to positively affect esteem for the patient with SUD. This project was congruent with the goal of changing detrimental behaviors and promoting positive self-esteem in patients with SUD. 
Healthcare providers can assist patients in their path to recovery by meeting their basic needs. The goal of self-actualization parallels with the goals of sobriety and recovery. With high morbidity and mortality rates for this population, rallying healthcare providers, as well as community members is more likely to be successful.

The short term objective was a change in awareness in attitudes and behaviors towards patients with SUD. This was achieved as evidenced by improvement in role adequacy and selfesteem. The intermediate objective was a change in the healthcare providers approach to the patient. The long term objective was improved patient outcomes. Ongoing evaluations will garner further information about sustainability.

\section{Future Implications}

The correlation between role support and job satisfaction should be emphasized. Providing nurses with the tools to care for this vulnerable population will not only improve patient outcomes, but staff resiliency as well. As the nation engages in the care of this vulnerable group, institutional efforts should be directed at supporting our caregivers. Furthermore, significant improvement was noted in two key areas; role adequacy and self-esteem. Empathy wanes and must be promoted, thus nurses would benefit from tools to promote empathy. Each nurse could potentially achieve self-actualization with organizational support. As role support is a top-down leadership buy-in, organizational administrators should be included in empathy training.

\section{Limitations}

This research study was limited by its small sample size, making it difficult to find significant relationships between the data. A larger sample size would ensure a representative distribution of the population making results more generalizable (USC Libraries, 2019). Many 
factors contributed to the sample size including inclement weather during data collection period in rural West Virginia and longitudinal effects of the short study time. Low response rate may have been due to the small size of the rural ED, many nurses who had biases may not have wanted to participate, and concerns about confidentiality could have decreased attendance, as well.

The intervention of this project was offered on five occasions. Offering the training on different shifts and departments many times throughout the year would yield more participants. Additionally, empathy training could be included in future annual training requirements.

The post intervention DDPPQ was returned within two weeks to ensure data collection for this time sensitive study. Longer return times would allow the participant ample time to apply new knowledge in their practice. Furthermore, implicit bias against those who have SUD could have confounded the data. Expanding the project to include all staff who have patient contact would be beneficial. As well, offering various sessions without time constraints would increase participation.

\section{Conclusions}

Incorporating empathy training into the culture of the hospital would normalize it and likely increase participation as well. This aligns well with the mission of the hospital 'We Care for Life', as empathy is an expression of care (DMC, 2016). Future phases of this incorporation could be directed by the education department. The process of this project included an interactive dialogue to promote empathy, however, other formats such as commercial videos could be considered for use. 


\section{Attainment of DNP Essentials}

\section{DNP Essential I: Scientific underpinnings for practice}

This nursing discipline focuses on the principles and laws that govern the life-process, well-being, and optimal function of human beings, sick or well (American Association of Colleges of Nursing $\{\mathrm{AACN}\}, 2006)$. The scientific underpinnings of SUD were shared using up to date evidence based medicine from a broad perspective, integrating neurobiology, healthcare, criminal justice and community.

\section{DNP Essential II: Organizational and system leadership for quality improvement and} system leadership

Quality improvement and system leadership was demonstrated, highlighting a pervasive culture of detached care that lacked true patient engagement and empathetic care. This project developed an effective strategy for managing the ethical dilemmas inherent in this marginalized population, the health care organization, and research.

\section{DNP Essential III: Clinical scholarship and analytical methods for evidence based practice}

Analytic methods to critically appraise existing literature were completed with this projects literature review and synthesis. That information was the then used to determine and implement the best evidence for practice, in this case, using patient stories to promote empathy. The disseminated findings demonstrated that promoting empathy has the ability to improve healthcare outcomes (Williams, Brown, McKenna, 2013).

\section{DNP Essential IV: Information Systems/Technology and Patient Care Technology for the}




\section{Improvement and Transformation of Health Care}

SPSS was used to evaluate the effectiveness of this intervention. Utilizing this database permitted the ability and technical skills to develop and execute an evaluation plan involving data extraction from practice information systems and databases (AACN, 2006).

\section{DNP Essential V: Health Care Policy for Advocacy in Health Care}

Developing a tool to promote empathy for a vulnerable population exemplifies advocacy in healthcare. Identifying weaknesses in strategic plans and cultures provided the opportunity to improve care and ultimately improve patient outcomes. Patients with SUD need healthcare advocates in all healthcare arenas.

\section{DNP Essential VI: Interprofessional Collaboration for Improving Patient and Population}

\section{Health Outcomes}

Implementing any project requires interprofessional collaboration. This student investigator was fortunate to have the support of the $\mathrm{COO}$ of the small rural hospital, as well as the ED nurse manager. This study has the ability to influence standards of care to include empathy. Promoting empathy, particularly in the Emergency Department, could be transformative and improve population health outcomes for those with SUD.

\section{DNP Essential VII: Clinical Prevention and Population Health for Improving the Nation's}

\section{Health}

SUD has the highest rate of morbidity and mortality of any other preventable health condition (National Institute on Drug Abuse, 2017). Promoting empathy for this vulnerable population has the potential to improve patient outcomes.

\section{DNP Essential VIII: Advanced Nursing Practice}

Evaluating a tool to promote empathy for patients with substance use disorder involved a 
comprehensive and systematic assessment of health and illness parameters in complex situations, incorporating diverse and culturally sensitive approaches (AACN, 2006). Conceptual and analytical skills in evaluating the links among practice, organizational, population, fiscal, and policy issue were exemplified in this advanced practice role. 


\section{References}

American Association of Colleges of Nursing. (2006). The essentials of doctoral's education for advanced practice nursing. Retrieved from https://www.aacnnursing.org/DNP/DNPEssentials

Cohen, L. G., \& Sherif, Y. A. (2014). Twelve tips on teaching and learning humanism in medical education. Medical Teacher, 36(8), 680-684. doi:10.3109/0142159X.2014.916779

Davis Health System, (2016). About us. Retrieved from https://www.davishealthsystem.org/about-us/our-mission-vision

Dickens, G. L., Lamont, E., \& Gray, S. (2016). Mental health nurses' attitudes, behavior, experience and knowledge regarding adults with a diagnosis of borderline personality disorder: Systematic, integrative literature review. Journal of Clinical Nursing, 25(1314), 1848-1875. doi:10.1111/jocn.13202

Fleming, B. D., Thomas, S. E., Shaw, D., Burnham, W. S., \& Charles, L. T. (2015). Improving Ethnocultural Empathy in Healthcare Students through a Targeted Intervention. Journal of Cultural Diversity, 22(2), 59-63.

Gagan, M. (2017). Learning from experience. British Journal of Nursing, 26(20), 1092. doi:10.12968/bjon.2017.26.20.1092 
PROMOTING EMPATHY FOR PATIENTS WITH SUBSTANCE ABUSE DISORDER

Halpern, J. (2003). What is Clinical Empathy? Journal of General Internal Medicine, 18(8), 670-674. http://doi.org/10.1046/j.1525-1497.2003.21017.x

HealthStream (2018). Retrieved from

https://www.healthstream.com/resources/blog/blog/2018/02/16/organizational-goal-

setting-in-healthcare-best-practices

Henwood, B. F., Derejko, K.-S., Couture, J., \& Padgett, D. K. (2015). Maslow and Mental

Health Recovery: A Comparative Study of Homeless Programs for Adults with Serious Mental Illness. Administration and Policy in Mental Health, 42(2), 220-228. http://doi.org/10.1007/s10488-014-0542-8

Hojat, M., Bianco, J. A., Mann, D., Massello, D., \& Calabrese, L. H. (2015). Overlap between empathy, teamwork and integrative approach to patient care. Medical Teacher, 37(8), 755-758. doi:10.3109/0142159X.2014.971722

Legere, L., Nemec, P. B., \& Swarbrick, M. (2013). Personal narrative as a teaching tool. Psychiatric Rehabilitation Journal, 36(4), 319-321. doi:10.1037/prj0000030

Lim, B. T., Moriarty, H., Huthwaite, M., Gray, L., Pullon, S., \& Gallagher, P. (2013). How well do medical students rate and communicate clinical empathy? Medical Teacher, 35(2), e946-e951. doi:10.3109/0142159X.2012.715783

Logan, D. E., \& Marlatt, G. A. (2010). Harm Reduction Therapy: A Practice-Friendly Review of 
PROMOTING EMPATHY FOR PATIENTS WITH SUBSTANCE ABUSE DISORDER

Research. Journal of Clinical Psychology, 66(2), 201-214.

http://doi.org/10.1002/jclp.20669

Lown, B. (2016). A social neuroscience-informed model for teaching and practicing compassion in health care. Medical Education, 50(3), 332-342. doi:10.1111/medu.12926

McLeod, S. A. (2018, May 21). Maslow's hierarchy of needs. Retrieved from https://www.simplypsychology.org/maslow.html

Miller, S. R. (2014). A Patient-Centered Curriculum Can Improve Attitudes Towards and Advocacy for Persons with Disabilities. Medical Education, 4811.

Morrison, M. (2011). SWOT analysis for Nurses and Health care environments. Retrieved from https://rapidbi.com/swot-analysis-in-nursing-health-care/

National Institute on Drug Abuse. (2018). West Virginia opioid summary. Retrieved from https://www.drugabuse.gov/drugs-abuse/opioids/opioid-summaries-by-state/westvirginia-opioid-summary

NIDA. (2018, July 20). Drugs, Brains, and Behavior: The Science of Addiction. Retrieved from https://www.drugabuse.gov/publications/drugs-brains-behavior-science-addiction

NIDA. (2017, March 23). Health Consequences of Drug Misuse. Retrieved from https://www.drugabuse.gov/related-topics/health-consequences-drug-misuse

Plant, J., Barone, M. A., Serwint, J. R., \& Butani, L. (2015). Taking Humanism Back to the Bedside. Pediatrics, 136(5), 828-830. doi:10.1542/peds.2015-3042

Post, S. G., Ng, L. E., Fischel, J. E., Bennett, M., Bily, L., Chandran, L., \& ... Roess, M. W. 
PROMOTING EMPATHY FOR PATIENTS WITH SUBSTANCE ABUSE DISORDER

(2014). Routine, empathic and compassionate patient care: Definitions, development, obstacles, education and beneficiaries. Journal of Evaluation in Clinical Practice, 20(6), 872-880. doi:10.1111/jep.12243

Remy, L., Narvaez, J., Sordi, A., Guimarães, L. S. P., Von Diemen, L., Surratt, H., ... Pechansky, F. (2013). Correlates of unprotected sex in a sample of young club drug users. Clinics, 68(11), 1384-1391. http://doi.org/10.6061/clinics/2013(11)01

Schmidt \& Haglund, (2017). Debrief in emergency departments to improve compassion fatigue and promote resiliency. Journal of Trauma Nursing, 24, p 317 - 322. Retrieved from https://www.nursingcenter.com/cearticle?an=00043860-2017090000009\&Journal_ID=607948\&Issue_ID=4326252

Sng, G., Tung, J., Yeo, S. P., Win, M. M., Chan, Y. H., Hooi, S. C., \& Samarasekera, D. (2014). Empathy decline in medical school - The Uniquely Singaporean Perspective. Medical Education, 4816.

Strike, C., Rudzinski, K., Patterson, J., \& Millson, M. (2012). Frequent food insecurity among injection drug users: correlates and concerns. BMC Public Health, 12, 1058. http://doi.org/10.1186/1471-2458-12-1058

Substance Abuse and Mental Health Services Administration. Behavioral Health Barometer:

West Virginia, 2015. HHS Publication No. SMA-16-Baro-2015-WV. Rockville, MD: Substance Abuse and Mental Health Services Administration, 2015 
Sullivan, R. (2010). Fear in Love: Attachment, abuse and the developing brain. Cerebrum.

Retrieved from

http://dana.org/Cerebrum/2010/Fear_in_Love_Attachment,_Abuse,_and_the_Developin g_Brain/

The National Trauma Consortium. (2004). Enhancing substance abuse recovery through

integrated trauma treatment. Retrieved from https://www.samhsa.gov/sites/default/files/wcdvs-article.pdf

The U. S. Department of Housing and Urban Development (2016). The 2016 annual homeless assessment

report (AHAR) to congress. Retrieved from https://www.hudexchange.info/resources/documents/2016-AHAR-Part-1.pdf

USC Libraries, (2019). Research guides: Organiznig your social science research paper:

Limitations of the study. Retrieved from http://libguides.usc.edu/writingguide/limitations

Van Boekel L.C., Brouwers E.P.M., van Weeghel J., Garretsen H.F.L., (2013). Stigma among health professionals towards patients with substance use disorders and its consequences for healthcare delivery: Systematic review. Drug Alcohol Depend. 2013;131:23-35. doi:10.1016/j.drugalcdep.2013.02.018

Vivolo-Kantor AM, Seth P, Gladden RM, et al. Vital Signs: Trends in emergency department visits for suspected opioid overdoses — United States, July 2016-September 2017. 
MMWR Morb Mortal Wkly Rep 2018;67:279-285.

DOI: http://dx.doi.org/10.15585/mmwr.mm6709e1.

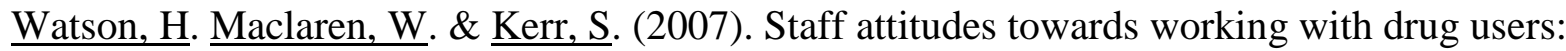

development of the Drug Problems Perceptions Questionnaire. Addiction, 102(2):206-15.

West Virginia Bureau for Behavioral Health and Health Facilities. (2018). West Virginia behavioral health epidemiological profile. Retrieved from http://dhhr.wv.gov/bhhf/resources/documents/2013_state_profile.pdf

Wiklund Gustin, L., \& Wagner, L. (2013). The butterfly effect of caring - clinical nursing teachers' understanding of self-compassion as a source to compassionate care. Scandinavian Journal Of Caring Sciences, 27(1), 175-183. doi:10.1111/j.14716712.2012.01033.x

Williams, B., Brown, T., \& McKenna, L. (2013). DVD empathy simulations: An interventional study. Medical Education, 47(11), 1142-1143. doi:10.1111/medu.12343 


\section{Appendix A}

\section{DRUGS AND DRUG USERS' PROBLEMS PERCEPTIONS QUESTIONNAIRE (VALIDATED VERSION)}

To which professional group do you belong? [These categories have been modified from the original version] Psychiatrist__ Nurse___Addiction Counselor__ Social Worker___Psychologist___ Peer Counselor

What is your clinical specialty?

How long have you held this post?

Please indicate how much you agree or disagree with each of the following statements about working with people who use illicit or legal drugs in a non-therapeutic way.

\begin{tabular}{|l|l|l|l|l|l|l|l|l|}
\hline \multicolumn{1}{|l|}{$\begin{array}{l}\text { PLEASE CIRCLE ONE NUBER FOR EACH } \\
\text { QUESTION }\end{array}$} & \multicolumn{3}{|c|}{$\begin{array}{c}\text { Strongly Strongly } \\
\text { Agree }\end{array}$} \\
\hline 1. & I feel I have a working knowledge of drugs and drug related problems. & 1 & 2 & 3 & 4 & 5 & 6 & 7 \\
\hline 2. & $\begin{array}{l}\text { I feel I know enough about the causes of drug problems to carry out } \\
\text { my role when working with drug users. }\end{array}$ & 1 & 2 & 3 & 4 & 5 & 6 & 7 \\
\hline 3. & $\begin{array}{l}\text { I feel I know enough about the physical effects of drug use to carry out } \\
\text { my role when working with drug users. }\end{array}$ & 1 & 2 & 3 & 4 & 5 & 6 & 7 \\
\hline 4. & $\begin{array}{l}\text { I feel I know enough about the psychological effects of drugs to carry } \\
\text { out my role when working with drug users. }\end{array}$ & 1 & 2 & 3 & 4 & 5 & 6 & 7 \\
\hline 5. & $\begin{array}{l}\text { I feel I know enough about the factors which put people at risk of } \\
\text { developing drug problems to carry out my role when working with } \\
\text { drug users. }\end{array}$ & 1 & 2 & 3 & 4 & 5 & 6 & 7 \\
\hline 6. & I feel I know how to counsel drug users over the long term. & 1 & 2 & 3 & 4 & 5 & 6 & 7 \\
\hline 7. & $\begin{array}{l}\text { I feel I can appropriately advise my patients/clients about drugs and } \\
\text { their effects. }\end{array}$ & 1 & 2 & 3 & 4 & 5 & 6 & 7 \\
\hline 8. & $\begin{array}{l}\text { I feel I have the right to ask patients/clients questions about their drug } \\
\text { use when necessary. }\end{array}$ & 1 & 2 & 3 & 4 & 5 & 6 & 7 \\
\hline 9. & $\begin{array}{l}\text { I feel that my patients/clients believe I have the right to ask them } \\
\text { questions about drug use when necessary. }\end{array}$ & 1 & 2 & 3 & 4 & 5 & 6 & 7 \\
\hline 10. & $\begin{array}{l}\text { I feel I have the right to ask a patient for any information that is } \\
\text { relevant to their drug problems. }\end{array}$ & 1 & 2 & 3 & 4 & 5 & 6 & 7 \\
\hline
\end{tabular}




\begin{tabular}{|c|c|c|c|c|c|c|c|c|}
\hline 11. & $\begin{array}{l}\text { If I felt the need when working with drug users I could easily find } \\
\text { someone with whom I could discuss any personal difficulties that I } \\
\text { might encounter. }\end{array}$ & 1 & 2 & & 4 & 5 & 6 & 7 \\
\hline 12. & $\begin{array}{l}\text { If I felt the need when working with drug users I could easily find } \\
\text { someone who would help me clarify my professional responsibilit }\end{array}$ & 1 & 2 & & & 5 & 6 & 7 \\
\hline
\end{tabular}

\begin{tabular}{|c|c|c|c|c|c|c|c|}
\hline \multicolumn{2}{|r|}{$\begin{array}{l}\text { PLEASE CIRCLE ONE NUBER FOR EACH } \\
\text { QUESTION } \\
\end{array}$} & \multicolumn{6}{|c|}{$\begin{array}{c}\text { Strongly Strongly } \\
\text { Agree Disagree }\end{array}$} \\
\hline 13. & $\begin{array}{l}\text { If I felt the need I could easily find someone who would be able to help } \\
\text { me formulate the best approach to a drug user. }\end{array}$ & 1 & & 4 & 5 & 6 & 7 \\
\hline 14. & I want to work with drug users. & 1 & 3 & 4 & 5 & 6 & 7 \\
\hline 15. & I feel that there is little I can do to help dru & 1 & 3 & 4 & 5 & 6 & 7 \\
\hline 16. & $\begin{array}{l}\text { In general, I have less respect for drug users than for most other } \\
\text { patients/clients I work with. }\end{array}$ & 1 & 3 & 4 & 5 & 6 & 7 \\
\hline 17. & $\begin{array}{l}\text { I feel I do not have much to be proud of when working with drug } \\
\text { users. }\end{array}$ & 1 & 3 & 4 & 5 & 6 & 7 \\
\hline 18. & At times I feel I am no good at all with drug users. & 1 & 3 & 4 & 5 & 6 & 7 \\
\hline 19. & On the whole, I am satisfied with the way I work with drug users. & 1 & 3 & 4 & 5 & 6 & 7 \\
\hline 20. & In general, one can get satisfaction from working with drug users. & 1 & 3 & 4 & 5 & 6 & 7 \\
\hline 21. & In general, it is rewarding to work with drug users. & 1 & 3 & 4 & 5 & 6 & 7 \\
\hline 22. & In general, I feel I can unde & 1 & 3 & 4 & 5 & 6 & 7 \\
\hline
\end{tabular}

Retrieved from: http://www.scotland.gov.uk/publications/2003/08/17735/23453 


\section{Appendix B}

Capstone Budget Plan Form and Justification

\begin{tabular}{|c|c|c|}
\hline Budget Categories & Personal Funds & Organizational Contributions \\
\hline ADMINISTRATIVE COSTS & $\begin{array}{l}\$ 135.00 \text { (donated } \\
\text { lecture time) }\end{array}$ & $\begin{array}{l}\$ 911.64 \text { (will add provider } \\
\text { salary estimates later) }\end{array}$ \\
\hline \multicolumn{3}{|c|}{$\begin{array}{l}\text { The staff salary for attending the lectures will be met by the DMC as an organizational } \\
\text { contribution. } \\
\text { An average Nurse Practitioner salary } \$ 45 / \mathrm{hr} . \times 3 \mathrm{hr} . / \mathrm{yr}=\$ 135 \text {-this is my donated lecture time } \\
\text { Average RN salary } \$ 26.56 \times 32 \mathrm{RNs}=\$ 849.92 \text { plus average LPN salary } \$ 15.43 \times 4 \mathrm{LPNs}= \\
\$ 61.72 \text { in DMC ED }=\$ 911.64 \text { (organizational cost) }\end{array}$} \\
\hline MARKETING & $\$ 0$ & $\$ 0$ \\
\hline \multicolumn{3}{|c|}{$\begin{array}{l}\text { Marketing justification: No marketing plans at this time other than briefing at the hospital via } \\
\text { email }\end{array}$} \\
\hline $\begin{array}{l}\text { EDUCATIONAL } \\
\text { MATERIALS/ INCENTIVES }\end{array}$ & $\$ 10$ & $\$ 0$ \\
\hline \multicolumn{3}{|c|}{$\begin{array}{l}\text { Educational Materials/Incentives justification: } \$ 0 \\
\text { I will be contacting the Education Director of the Emergency Department to offer CEUs for } \\
\text { the nurses who attend my lecture. (Organizational contribution) }\end{array}$} \\
\hline $\begin{array}{l}\text { HOSPITALITY (food, room } \\
\text { rentals, etc.) }\end{array}$ & $\$ 0$ & $\$ 0$ \\
\hline \multicolumn{3}{|c|}{ Hospitality justification: The lecture room will be an organizational contribution } \\
\hline $\begin{array}{l}\text { PROJECT SUPPLIES (office } \\
\text { supplies, postage, printing, etc.) }\end{array}$ & $\$ 50$ & $\$ 50$ \\
\hline \multicolumn{3}{|c|}{$\begin{array}{l}\text { Project supplies justification: I will use my personal computer and PowerPoint projection is } \\
\text { already in place at the hospital, there will be no additional cost for these services. } \$ 50 \text { is } \\
\text { being budgeted for IT to set up a webinar recording of one lecture for future use by DMC if }\end{array}$} \\
\hline
\end{tabular}


they decide to incorporate empathy training after my pilot study is completed. $\$ 50$ is being budgeted for printing of posters for sustainability

TRA VEL EXPENSES

$\$ 75.60$

$\$ 0$

Travel expenses justification: Travel to DMC 3 times x 30 miles each way for a total of 6 trips at .42 cents $/$ mile $=\$ 75.60$ mileage $($ volunteered time on my part)

TOTALS

$\$ 270.60$

$\$ 961.64(+x)$ 


\section{Appendix C}

Key site support

Letter

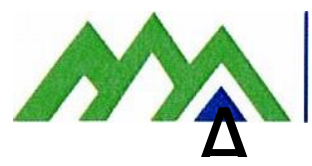

DavisHealthSystem

812 Gorman Avenue • Elkins, WV 26241 • 304.637.3767• Fax 304.637.3435•

davishealthsystem.org

September 5, 2018

West Virginia University

Institutional Review Board

RE: Doctorial Capstone Project of Theresa Poling, FNP-BC

Ladies and Gentlemen:

On behalf of Davis Medical Center, I want to express our full support for Theresa's planned capstone project related to educating our ED nursing staff about Substance Use Disorder. It is our hope that through such efforts we will discover how we can simultaneously improve patient engagement along with staff empathy and resilience.

In addition to myself, Theresa has met with leadership of our Education, Emergency and Pastoral Care departments to discuss and plan out details for her educational sessions and the pre and post surveys of staff related to Substance Use Disorder patients.

If you have additional questions regarding our support, please contact me. 


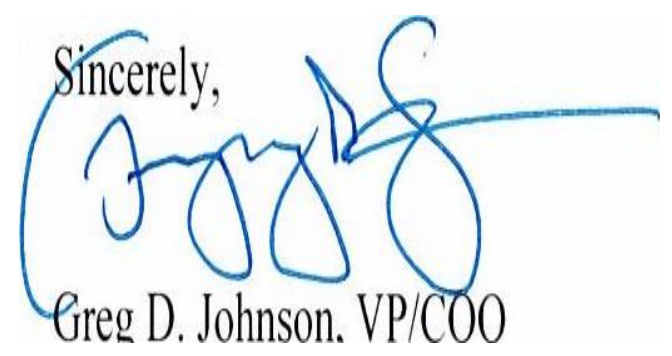

\section{Appendix D}

\section{SMART plan}

\begin{tabular}{|c|c|c|}
\hline Step & Concept & Description \\
\hline 1 & $\begin{array}{l}\text { Specific } \\
\text { Exactly what is it you want to achieve in your } \\
\text { business or personal life? A good goal statement } \\
\text { explains the what, why, who, where and when } \\
\text { of a goal. If your goal statement is vague, you } \\
\text { will find it hard to achieve because it will be } \\
\text { difficult to define success. }\end{array}$ & $\begin{array}{l}\text { To cultivate a culture of care with } \\
\text { local Emergency Department nurses } \\
\text { and thereby improve the quality of } \\
\text { care for patients with substance use } \\
\text { disorders. }\end{array}$ \\
\hline 2 & $\begin{array}{l}\text { Measurable } \\
\text { You must be able to track progress and measure } \\
\text { the result of your goal. A good goal statement } \\
\text { answers the question, how much or how many. } \\
\text { How will I know when I have achieved my } \\
\text { goal? }\end{array}$ & $\begin{array}{l}\text { Pre and post Likert Scale: Drug and } \\
\text { Drug Problems Perceptions } \\
\text { Questionnaire (DDPPQ) (Watson, } \\
\text { Maclaren, \& Kerr, 2007) }\end{array}$ \\
\hline 3 & $\begin{array}{l}\text { Agreed } \\
\text { Your goal must be relevant to your stakeholders } \\
\text { and agreed with them. Examples of people to } \\
\text { agree your goal with are your line manager, } \\
\text { employees and customers. }\end{array}$ & $\begin{array}{l}\text { My goal is in alignment with the } \\
\text { vision, mission and values of Davis } \\
\text { Memorial Center: Vision: We } \\
\text { Bring Better Health to Life } \\
\text { Mission: We Care for Life } \\
\text { VALUES: Safety • Quality • } \\
\text { Teamwork• Trust • Respect } \\
\text { - Courtesy }\end{array}$ \\
\hline
\end{tabular}




\begin{tabular}{|c|c|c|}
\hline 4 & $\begin{array}{l}\text { Realistic } \\
\text { Your goal should be stretching, but realistic and } \\
\text { relevant to you and your company. Make sure } \\
\text { the actions you need to take to achieve your } \\
\text { goal are things within your control. Is your goal } \\
\text { achievable? }\end{array}$ & $\begin{array}{l}\text { This DNP project is achievable as } \\
\text { evidenced by the precedent set in the } \\
\text { literature review }\end{array}$ \\
\hline 5 & $\begin{array}{l}\text { Time-Bound } \\
\text { Goals must have a deadline. A good goal } \\
\text { statement will answer the question, when will I } \\
\text { achieve my goal? Without time limits, it's easy } \\
\text { to put goals off and leave them to die. As well } \\
\text { as a deadline, it's a good idea to set some short- } \\
\text { term milestones along the way to help you } \\
\text { measure progress. }\end{array}$ & $\begin{array}{l}\text { Summer semester 2018: Meet with } \\
\text { COO (8-1-2018) /Complete draft } \\
\text { proposal } \\
\text { Fall semester 2018: Meet with } \\
\text { committee/chair approval/Submit to } \\
\text { IRB/Consent forms/advertise to } \\
\text { ED/Pre-test questionnaire to } \\
\text { experimental group and control } \\
\text { group/Clinical immersion/Develop } \\
\text { talk } \\
\text { Spring semester 2019: January: } \\
\text { Give talk } 3 \text { times/Give post-test } \\
\text { questionnaire/Continue clinical } \\
\text { immersion/Sustainability-begin to } \\
\text { execute reminders of empathy } \\
\text { Summer semester 2019: Meet with } \\
\text { statistician/Analyze data/Share data } \\
\text { with key stakeholders/Integrate } \\
\text { training into OB and ongoing } \\
\text { training with ED for } \\
\text { sustainability/Complete project } \\
\text { paper/Oral defense/ETD submission }\end{array}$ \\
\hline 6 & $\begin{array}{l}\text { Ethical } \\
\text { Goals must sit comfortably within your moral } \\
\text { compass. Most people resist acting unethically. } \\
\text { Set goals that meet a high ethical standard. }\end{array}$ & $\begin{array}{l}\text { This pilot study is ethical in that it is } \\
\text { theoretically based on help those } \\
\text { with substance abuse achieve the } \\
\text { areas identified in Maslow's } \\
\text { hierarchy of needs: Physiological, } \\
\text { safety, love and belonging, esteem } \\
\text { and self-actualization }\end{array}$ \\
\hline
\end{tabular}




\begin{tabular}{|c|l|l|}
\hline 7 & Recorded & $\begin{array}{l}\text { This project represents the } \\
\text { culmination of the following courses } \\
\text { Always write down your goal before you start } \\
\text { working towards it. Written goals are visible } \\
\text { and have a greater chance of success. The } \\
\text { recording is necessary for the planning, } \\
\text { monitoring and reviewing of progress. }\end{array}$
\end{tabular} \begin{tabular}{l}
$\begin{array}{l}\text { project has been saved and laid as } \\
\text { the building blocks of my project. }\end{array}$ \\
\hline
\end{tabular}

